\title{
The Horror of Urban Development in India - Identifying The Real Issues
}

\author{
Sebastian Morris
}

W. P. No. 2017-06-01

June 2017

The main objective of the working paper series of the IIMA is to help faculty members, research staff and doctoral students to speedily share their research findings with professional colleagues and test their research findings at the pre-publication stage. IIMA is committed to maintain academic freedom. The opinion(s), view(s) and conclusion(s) expressed in the working paper are those of the authors and not that of IIMA.

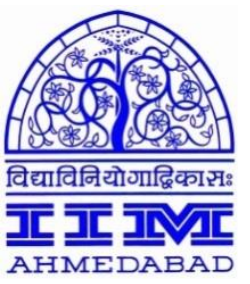

INDIAN INSTITUTE OF MANAGEMENT

AHMEDABAD-380 015

INDIA 


\title{
The Horror of Urban Development in India - Identifying the Real Issues ${ }^{1}$
}

\author{
Sebastian Morris ${ }^{2}$ \\ Indian Institute of Management, Ahmedabad
}

\begin{abstract}
The horror of India's urban spaces cannot be understood without recognizing the core errors in planning and in the approach of infrastructural development. These stem mainly from the low FSI's that are used, the lack of any recognition of central place needs of different economic activities, the lack of even a modicum of integration of transport planning with layout planning (the so called "Master Plans"), an" architects' approach" to urban design, and most importantly to the organization mess-up that the urban local bodies are. Unless these change the large sums of money that would be spent would actually result in much subtraction of social and public value.
\end{abstract}

${ }^{1}$ This was written in $15^{\text {th }}$ September, 2014, as a policy brief for the OECD, which was not used by the OCED, titled URBANISATION IN INDIA - Diagnoses and Challenges.

${ }^{2}$ Professor, Indian Institute of Management, Ahmedabad. Email: morris@iima.ac.in 


\section{INTRODUCTION}

Urbanization in a way that creates social value instead of subtracting from it, is the most important challenge that India faces today. There is little need to bring out in detail, the likely rates of urbanization in the future or of the infrastructural deficits, and the financing required for them. From about 35\% today the urbanization level is likely to increase to over $40 \%$ over the next 15 years. Urbanization, in India, is related to development (i.e.) per capita income (including of unrequited transfers from abroad) growth rather than industrialization per se.

The projections of the amount of investment etc. are not of much consequence being themselves dependent on projections of growth, which could change quite substantially. This is so because, as we will bring out below, the problem ultimately was never one of lack of fiscal resources, but one of the efficacy of government. We will argue that the growth patterns are dysfunctional, and largely so due to the flawed assumptions with which planning and regulation take place, so that public spending to improve the infrastructure is extraordinarily wasteful in Indian cities. Furthermore urban management is carried out in through organizations that are ill-structured (by law, design and management) with little ability to bear responsibility or accountability. So the mystery really is why Indian urban systems do not collapse altogether.

\section{GROWTH PROCESS}

The growth process since the reform of 1991-92, 1992-93 was based more on the export of tradable services (especially since 2003-04) and the spending multiplier effects of the vast remittances which have been grown at high rates to exceed by a wide margin the growth in overall GDP. So "income" including transfers, rather than growth in value addition, is the basic driver of urbanization in India. Only second in importance has been industrialization whose effects are large in Gujarat, Tamilnadu, Haryana and Maharashtra, states which have seen a rapid growth in manufacturing over the same period. Yet urban growth has been slower than that of China, which is not surprising since per capita income growth has been much slower than that in China.

Migration remains an important basis of urban growth since India is in the transition phase. Migration has varied across cities, and has been important for the most rapidly growing cities - 
Bangalore, Surat, Delhi etc. But the absolute numbers of those migrating have been far smaller than in China, though relative to the economic activity it is comparable. Urban growth thus far has been influenced more by the pull factor as exemplified by the slower growth of population in cities like Calcutta and Chennai over the 90s and 00s whose immediate hinterland, and the city have had less strong economic drivers for growth.

\section{Push factors to increase}

In the years to come, Urban population growth is likely to be increasingly affected by the push factor from rural India, as the agricultural sector shrinks below $12 \%$ and the "need" for labour productivity growth in Indian agriculture increases. With the family as the basis for sharing of agricultural income (even when the marginal product of labour in agriculture is close to zero) breaking down, it is likely that there would be the force of rural unemployed to increase the population especially of the slums, jhuggis and illegal spaces within the cities, to create a vast informal sector. (In Latin America the push factor has been very important and has inter alia created the vast shanty towns around Sao Paulo or Rio in the seventies and eighties).

\section{Embedding of rank size rule}

The core pattern in urbanisation is the emergence of the rank size rule especially in eastern India as the mid sized towns - Lucknow, Allahabad, Bhubaneswar besides Bokaro, etc. have grown somewhat faster than the city of Kolkata. In the colonial period Eastern India and to a less extent central-Western India had been cases of "extreme metropolitan" development. In the West, South and North West which even in the late colonial period had seen a movement towards rank size rule, the trend in that direction has held and may have even accelerated as mid-sized towns Jaipur, Bhopal, Nasik, Coimbatore, Cochin etc. have emerged as larger cities. There has also been a greater internal (economic and human) articulation across cities. But more so in the Southern, Western and North-Western parts of the country which have also progressed faster in overall development, especially since 1992-93. The internal trade has been growing somewhat faster than global trade both of which have grown faster than GDP as is to be expected in an emerging economy that is in the early stages of its transformation. 


\section{City forming functions in some cities}

Particular cities linked to the most dynamic sectors of the economy have grown significantly more rapidly than others often at the cost of other cities in their region as well - Bangalore (on software exports) in the South at the expense of Chennai; Surat (diamonds) in the West, Ernakulam (remittance spending effects), Delhi complex (vast spending of central and Delhi governments besides IT-BPO) in the North-West, Lucknow (being one of the few cities where there is law and order in the region). Pune (West), Hyderabad (South) have also received significant impetus from the growth of the IT-BPO sectors.

Manufacturing policies barring most notably in the automobile sector, and pharma, have been particularly adverse (especially in comparison to China). This has affected nearly all tradable industries especially those with low transport and logistic costs per unit of value. More than the lowering of duties the adverse exchange rate (the real value of the rupee having depreciated and the Indian rupee being overvalued in relation to the Chinese and other east Asian especially Thai currency), the very high interest rates, and the policy of "equilibrium" management of the balance of payments (i.e. allowing private inflows to cover trade deficits) has allowed the "Dutch disease" like effect of the success of ITES and remittances, to create a large bias against mfg. in India. ${ }^{1}$

\section{INFRASTRUCTURAL DEFICITS}

Only housing and commercial real estate (however inappropriate the location) deficits have reduced significantly in the two decades since the reform. But to give a sense of the deficits especially in publicly provided services the following may be noted

\footnotetext{
${ }^{1}$ Thus nearly $90 \%$ of the domestic market for electronics goods is served by imports. The new government though is keen on the growth of manufacturing recognizing its vast potential to provide employment and is likely to be not deterred by policy orthodoxy of a "liberal" economy, but is likely to draw much from China and East Asia. Thus it is possible that it could come out with policies that create a wedge between the prices of CKDs in electronics and fully assembled products. Such a policy could lead to very rapid growth of manufacturing to (in the future) absorb the surplus labour being pushed out of the rural areas from agriculture. Over the last decade much of the surplus labour out of agriculture as incomes have risen have been "absorbed" as household labour as women farm workers now stay at home, especially in northern and western India. Going forward the surplus labour from agriculture would be most men who would then swell the unemployed in the informal sector (most likely) or perhaps be absorbed by a rising manufacturing sector if the new government is able to get its act together to create a policy environment and public service provisioning that is conducive to manufacturing development.
} 


\section{Woeful state of water and sanitation}

Less than $50 \%$ of the population is covered adequately by municipal supplies of drinking water. The ground water / trucked water dependence has increased in most cities The sewerage system covers well below $100 \%$ usually less than $70 \%$ of the population even in the very best of situations. Nowhere is the water quality good and there is almost no city where the supplies are $24 \times 7$. Wastage is as high as $40-60 \%$. The enormity of the social (and more specifically health) costs paid by this less than $100 \%$ sewerage has not been adequately recognized by even international experts.

\section{Unclean as can be}

India has very high morbidity in the world and there is no part of the soil and dust of any city barring perhaps those in the North East, is not contaminated by fecal matter. As many as $25 \%$ of the population do their toilet in the open in Mumbai's premium city making no part of the city free of the stench of human faces. Open defecation even in a well-managed city Ahmedabad is common. There are 119 places in the city where open defection takes place there, and India is very far from abolishing what it has ruled in its constitution as a crime viz. manual scavenging. The apathy and lack of understanding that the failure lies in the state, and is easily corrected even with a modicum of the right action is condemnable. The high disease burden and bacterial load also adversely affects MMR, infant mortality death in hospitals, quality of life. The ill-effects are masked by the availability of cheap antibiotics and cheaper doctors which keeps adult deaths low even as the disease morbidity remains high.

\section{Electricity supplies have not improved}

Quality of electricity supplies varies from city to city and even more from location to location. Only Gujarat has near 24X7 supplies. Most other states would have their capital cities where the elite congregate with near $24 \times 7$ supplies, but most other cities have frequent power cuts making life in the summer months to most people unbearable when these cuts are on. Over now more than a generation of denial, coping strategies have emerged with the better off, and commercial businesses like the larger shops being able to provide themselves with back up battery storage and 
gensets, the combined investments would exceed many fold the cost of investments in the utilities to overcome the shortages.

\section{Even primary health care ails}

Primary health care in urban India is patchy but in comparison to the failure in drinking water, sewerage and sanitation, can be considered as better. In the cities of Tamilnadu and Kerala, and in many cities in Karnataka and Maharashtra state provision is passable, but in most others there is glaring failure. In some states like Bihar even inoculation programmes have not met their targets and there are large numbers of children who even today are victims of entirely avoidable diseases.

\section{The chaos of transportation design}

The share of private and para transport has everywhere increased. The share of potentially social value enhancing public transport has declined almost everywhere. The share of private motorized transport especially the ubiquitous two-wheeler has gone up sharply in urban India. In urban places with much higher per capita incomes - Delhi, Goa, Ernakulam, Ahmedabad etc. cars now do a significant part of the commuting. In rural India the motor cycle has become the main mode of transport being point to point, relatively cheap and being much less affected by the poor condition of the roads. With the ubiquitous role of private transport by "two-wheelers" even when public transport is provided is not easy to displace since vehicle purchase costs become sunk costs, and the point to point aspect becomes very important given the sprawl layout of most cities. (The reasons for the same we shall soon see.

\section{Even vast funding has not improved the situation}

Since the JNNURM significant financial outlays have been made to improve urban public transport through support for bus purchases, metros and BRTS but has not been able to make a significant dent into the use of public transport or in reducing commute times. Many are still under construction. But even those constructed the usage has been less than planned - in Chennai the metro investments made in the eighties have all but gone completely waste. Similarly the suburban rail south of Kolkatta is used more like a branch line than a metro-suburban, the ring railway in Delhi built in the seventies having no convenient interconnect with the roads was 
hardly used and then neglected by the railways to result in a spiral of low use, declining frequencies to completely kill the system. Even the newer metros - Delhi - the construction of which was flawlessly executed and interestingly without much inconvenience to the residents ${ }^{2}$ has a layout that is based on the old city centre (Connaught Place - Parliament) while the new centre (downtown) is Gurgaon, so that many of the lines are underutilized while some -notably the line to Gurgaon is running to capacity. Other problems arise because DMRC does not have appropriate financial incentives to run trains more frequently but avoids losses when it packs the trains - so that large public value losses take place.

\section{TOWN PLANNING AND TRANSPORT NETWORKS}

\section{FSI and large capacity public transport}

The lack of any sort of coordination between town planning authorities and the Delhi Metro means that Delhi metro has not been able to raise the FARs/FSIs to high levels around the metro corridors -not even near stations, so that the large potential for use of the metro is unrealized the potential to walk in and walk out as part of shopping and work commutes. The same problem continues to hold back the value metros since most municipalities do not know how they could increase the FARs/ FSIs, without creating windfalls for landowners and builders. Additionally the lack of any kind of coordination with other local transport modes -bus, para, taxis, airports, railways, means that the multimodal is about as distant as can be, reducing the value of public transport to users. Pedestrian crossings have become all but impossible in many cities for pedestrians. But when used nearly always result in traffic being held up. The intrusion of pedestrains and traffic on each other is rampant except perhaps in the very core of the city Lutyen's Delhi for example.

\section{Suboptimal network design}

Delhi has more road surface to built-up areas or even vehicles than most other cities in the world. Yet it has severe traffic jams and very slow movement of traffic. The reason is not the increasing population of cars as is generally believed to be. The reasons lie in poor design of road systems -

\footnotetext{
${ }^{2}$ All construction in urban areas in notorious for the humongous inconvenience, and losses they impose on citizens.
} 
angular intersects with multiple radial systems, which were put in place over Lutens Delhi, ribbon rather than corridor development. Even when multiple roads in an arterial direction is possible only a few or even one would be used because of the other roads being "sealed" off, there being breaks in the continuity of most parallel roads. These problems of design especially ribbon development and lack of multiple parallel roads being used, are quite common across the large cities of India. Traffic therefore falls on a few roads.

\section{Increasing the friction in interaction}

The resulting highly distorted traffic pattern which is in part due to faulty design and usage distortion, when used as input to further planning and investment choices then leads to suboptimal investments, such as very expensive road widening flyover construction etc when what may have been more appropriate would have been opening up of "closed" roads and elevated highways, and operating the roads on a hierarchical basis, and breaking the continuous ribbon on the sides of a road to more cross roads that provide improved access to a wider area in the city.

In denser shopping areas sidewalks are not continuous (being more appropriate for housing than commercial blocks), so that walkers and hawkers come on to the streets reducing their capacity. The practice of "lazy (planning) reform" - one notable example of which is to allow commercial activities around all roads with a certain width (increasingly being adopted by cities following its introduction in Ahmedabad), while it certainly provides for more land use by commercial activities compounds the problem of traffic movement even when the roads as wide -as in the case of Ahmedabad.

The rational way would have been for planned change in land use with growth -residential in the fringe of the centre being converted to commercial in whole blocks, and similarly at subcentres (railway junctions, metro stations etc)), to spread the commercial activities right across the city recognizing the order of the many commercial activities.. With the increased use of private modes of transport, this irrational mixed use clobbers up street space for parking and informal activities slowing down movement on practically all the arterial ways in the city, including "expressways".

The only way then to keep even moderate speeds on certain crucial arteries is to make them very large to accommodate six or even eight lanes right in the middle of the city which then creates 
high load of traffic for merely going from one side of the "super way" to the other, because in effect (in terms of the actual activities around shopping and services) these roads are actually streets.

Barring the above dysfunctional practice of automatically allowing of commercial use on either side of a large road irrespective of whether it is an artery or a street, there is little integration between land use planning and transport planning. Indeed until recently even the central ministry of urban development did not see the same as being necessarily jointly determined. The "Master Plans" are the worst offenders in this respect. They only provide for a layout that diagrammatically provides access to every house/ block. But the simulations on how much traffic each segment would have, the load flow characteristics of traffic and movement, or the implications of artistic intersections roundabouts rather than intersections, the land use proposed and existing on the traffic in each segment are not even posed forget about a methodology being in place to properly analyse the same. Ring roads, which multiply the movements in relation to radials, are seen as the solution only accelerating the spread of the city as a sprawl.

\section{Unaffordable real estate}

The problem of high costs of housing and real estate spaces in Indian cities is well known. Thus Mumbai a city in a country of less than US\$ 1300 per capita income has one of the highest real estate prices. Not only in the downtown area which is very high priced, but even in the periphery the prices tend to be higher than in most other cities in the world. This makes the cost of housing, even of the most basic variety so utterly out of the reach of the poor especially in the metropolitan cities like Bangalore, Delhi, Pune and Mumbai. They are therefore forced to live in illegal spaces since the option of going to the periphery is often out of question given their need to access work opportunities. The general belief is that this is due to India's large population and high immigration to cities. The rate of immigration to cities has been lower than in all east Asian countries and the level of urbanization is significantly lower than in East Asia, many of whom have overcome the worst problems of urban congestion. 


\section{DYSFUNCTIONAL LAND USE AND PLANNING}

The real reasons for the same lie in the overall assumptions with which city planning is pursued and policies associated with land use:

(1) The assumption that land use by cities would come at a sacrifice of agriculture means that less land is released for urban use than is desirable. Most planners (if at all they are conscious of the basis of their rules and restrictions on use) would are guided by the false "Ricardian Model" of land rather than the more correct neo-classical model which allows for multiple uses so that the social cost of restriction in terms of suboptimal use are in part recognized, which is not the case with the Ricardian Model.

(2) Many states have a policy of requiring "Non Agricultural Clearance" (NAC) for use of agricultural land. This is not granted to farmers, but only selectively to builders and aggregators of land. The value jump-up in the grant of NAC is so large often as much as 5- 10 times, that "developers" and even early buyers of properties have strong incentives to leave large swathes without construction since their acquisition cost is low and they can risk the small loss of holding for the large gains in appreciation in the years that follow NAC. Also patchy provision of infrastructure by the municipal authorities further compounds the problem. The result is that of the total area that be considered as being in the city (as measured by the proportion of commuting population) - roughly captured by the Census definition of urban agglomerations, a significantly large part is not built up or put to any use at all.

(3) The practice of wasteful central use by "authorities" like the army (who hold vast cantonment lands in the heart of many cities -Pune, Bangalore, Kanpur), or of elite organisations like golf clubs right in city centres, very low density of use in the elite areas all reduce the available supply of built-up spaces that are not inconveniently located, subtracting a great deal from the social value.

(4) Even when land is released for urbanization the need is often bloated up by the low FSIs used. The combination of (2), (3) and low FSIs is to increase the wedge between the price of housing at the pheriphery and the cost of construction and of land associated but now 
in agriculture use. This wedge which naturally takes the form of rents creating vast corruption and entrenched mafias in the land acquisition, aggregation and clearance part of the business.

(5) Uncompensated restrictions on land use (over and above low FSIs) are very common and take a variety of forms. Restrictions near water bodies, old military establishments, existing airports etc which could perhaps have been anticipated by the land owner are common. Adhoc restrictions imposed by a sudden green consciousness can result in an uncompensated green area over private lands whose values then are depressed. Similarly, protection of monuments, historical buildings and other areas as being important for cultural and ecological reasons can take the form of restrictions on construction in nearby areas which are almost always uncompensated, putting much stress on the ability of market to reflect prices that are efficient in an allocative sense.

(6) Similarly land use restrictions and enhancements (such as a shift from residential use to commercial use) which take place through he master plans are almost entirely uncompensated. Sharp discontinuities in prices are the order of the day and which can change dramatically with administrative decisions of governments both state and municipal.

(7) Typically once land use is determined it hardly ever changes. Even the master plans which happen once in a decade or more do not typically adopt land use changes and densification. Routine changes from low order land use to a higher order land use is nearly completely absent.

(8) The very low FSIs, land use restrictions, vast swathes of unused land, planned provision of inefficient land use, puts large price pressure on real estate that happen to have favorable location and which were luckily allowed for more appropriate use.

\section{DYSFUNCTIONAL GROWTH PROCESSES}

A generalized process of dysfunctional growth is on in nearly all large cities in India which may be described stylistically as follows: 
The formal city under master planning and land use restrictions has little scope for growth. FSIs are very low and are not increased as the population of the city grows. The total built up area therefore does not rise in the areas of high locational value making the price of built up spaces very high in these areas. The Master Plan may have even laid out the core of the new urban place or alternative "centre" very lavishly to make real estate very expensive in the new urban area as well. The problem is compounded by elitist notions that drive the Master Plan -multiple roads, spreading out commercial, denying densification, non-integration with public transport so that in new places private transportation becomes almost a necessity. Nevertheless, the population continues to increase with the built up area per person declining, and many occupying illegal spaces such as public lands, roadsides, interstices between government buildings.

Any left over islands where the planning could not be extended (mostly due to property rights contest) then become dense with people at very low built up space per person. If the adherence to the highly restrictive norms is enforced then squatter settlements come about in the periphery, with unregulated construction, since legally these may still be under a different town administration or may even technically be a village.

A decade or so after new construction has come up in the periphery and in some direction more strongly than in others, regulation emerges there and the Master Planning is extended to the same as the city takes over the this town or original village. Soon enough the ridiculously low FSIs are again imposed which could shift the active centre of the city once more. Thus Ahmedabad's city centre has jumped from the walled area (where no new construction is at all possible) to Ashram Road in the immediate post independence period, and then to CG Road and now to SG Rd. Delhi saw its centre jump from Connaught Place to a set of locations (Nehru Place, Yeshwant Place) and then again to Gurgoan as the area under the NDMC was regulated to "death".

In smaller cities a by-pass road is usually planned to take the pressure of through traffic out of the city. The city itself would most probably have been using very low FSI's to constrain the addition of built up spaces. Poor investments in infrastructure especially city roads - not only because of funding issues - but also because of low density which amplifies the cost of unit infrastructure, as also whatever limited development being ribbonised, would mean that the citizens would be on the look out for a road with vacancy on it to build their shops and houses. 
As soon as a bypass road is in place in about 5 years that becomes the new site for construction for housing and the dynamic real estate market. Being unregulated till the planning authorities extend their domain to the area the by-pass now becomes the hive of activity. Indeed this phenomenon is nearly ubiquitous in the smaller cities. Even in many of the larger cities the phenomenon can be observed - Ernakulam bypass for the city of Cochin-Ernakulam, SG road for Ahmedabad, New HN-4 and Sholapur in Pune, the Ghodbander bypass in North, North-East Mumbai to name a few.

These patterns of ribbonised development along a bypass, or a ring-road, or the phenomenon of city central place shifting imposes large costs not to provide infrastructure, and loss of social value as well.

\section{THE INDIAN PATTERN OF CITY "DEVELOPMENT"}

The dysfunctionalities arising out the development process described above are many and can be listed as follows:

The process leaves vast spaces in the city which are not used at all, increasing the cost of infrastructure since all network infrastructure roads especially sewerage and water so expensive that they become beyond the capacity of the state at the existing levels of taxation to provide. The urban habitats then take the form of sprawls with no internal specialization of hierarchy of urban activities. The sprawl with low density means that public transportation especially of the high thruput mode (metro and train) are not as socially viable as they could otherwise have been with planned densification linked to metro/road infrastructure, giving rise to a very rapid growth of coping private and paratransport modes.

The haphazard growth means that most roads are an afterthought at best linking a habitat to a ribbonised road head. So directional multiple road ways are out of question bringing all traffic loads on a few arteries which are also likely to have been ribbonised. Commute times are very high which further prevents efficient location of activities. Most commercial activities then lack scale creating a bias against efficient retail especially of higher order goods and services. 
Road expansion and improvements then gets focused on a few arterials which becomes a very expensive proposition due the very high land costs around the arteries. Litigation given the dysfunctionalities in the land acquisition law and framework further compounds the problem taking even simple construction like a flyover take years.

Imposing hierarchy on the road system, even if taken up (which is rarely the case) becomes all but impossible without a strategy for coordinated reconnect of the various roads and railway systems.

The stretched costs of sewerage and sanitation systems, besides piped water, then means that the provision of these lag significantly the demand leading to coping strategies on the part of people open defecation, open gutters and sewers- all of which make Indian cities among the dirtiest in the world.

When highways and bypasses are so internalized, then these very roads and infrastructure act to isolate portions of the city creating a wedge between geographical closeness and closeness in terms of movement, greatly enhancing the number of road crossing people have to undertake which are high risk activities in India. Slow movement of traffic is a coping response to this irrationality in evolution. The option of cover-over of such earlier highways, by building public spaces over the road, especially near very their intersections, as a way out, is not even in the radar of city planners/ executives.

Besides low FSI norms, bye-laws governing buildings (building codes) further restrict the use of land in constructing built up spaces. Thus certain calculations show that on CG road in Ahmedabad in a $200 \mathrm{sqm}$ plot adjacent to the road it would not be possible to construct at all.

\section{MISSED OPPORTUNITY-ITES}

ITES which could have been an important source of dynamism to push urban spaces to a more functional orientation, have instead been driven by locational policy to put stress on cities. Thus the software industry being considered as an "industry", was pushed to Hosur Rd location in Bangalore where industries are normally located. There is logic (in terms of the possible negative externalities of industry on adjacent residential and commercial uses), in keeping industries at a distance from city centres and beyond their outer periphery. However ITES being office like in 
activity could have easily been co-located with residential, provided there were laws and norms to internalize the parking that ITES would require. Thus they would have come up in the middle class residential "ring" of most cities and the economic activity they generate could have provided an important impetus to the further all round growth of the city thereby simultaneously enhancing city serving and city forming functions.

Instead, by locating them at a great distance- and often with no road or rail infrastructure for people to access them easily, much time of the skilled IT worker is wasted in commute or expensive hostel accommodation has to be provided by the IT companies. All this subtracts from social value. An added 1 hour of avoidable commute time, it is estimated, takes away the equivalent of 10-15\% of the GDP of Bangalore! Even when finally a "high-speed" road corridor was put in place from the city to the IT park area on Hosur Rd, it was a "dedicated" elevated corridor with access at only the two ends, creating vast traffic jams near the Bangalore end. The opportunity to maximize the social value of an elevated corridor, by having connects from the elevated stretch to the road below at well spaced out intervals was completely missed, which would also have allowed multiple points of entry and exit reducing the congestion and extra car trips that the east-central Bangalore has to accommodate!

In Pune and the ITES industry has been located largely in the western periphery of the city which and constitutes a large part of the new urban areas. These areas being not too far from the older parts of the city does not result in as much social value loss as in the case of Bangalore. However in relation to using the investments for urban renewal in parts of the older city and their densification there is much social value loss.

\section{LAND TITLES AND REAL ESTATE}

This is a problem now being recognized. The problem is that there are no titles as such except in very old urban areas. What serves as title are the land revenue records at village offices. But encumbrances and power of attorney based agreement to sell are stored as records in the registrar office (typically under finance dept) since there is a stiff stamp duty involved ${ }^{3}$. The delay between the recording of these encumbrances and/or the sale with the revenue record has result in multiple sale and false sales etc. Large stamp duties make people use agreements to sell with only one-

\footnotetext{
${ }^{3}$ Only now beginning to be rationalized.
} 
final sale where stamp duty is paid. Adherence is therefore the issue, which therefore leaves all but the local mafias in the land aggregation business. Titles are so insecure that a title insurance market cannot exist. Similarly two properties with near identical locational factors could vary in their price by as much as $50 \%$ or more, with the one being sold by government commanding the premium since here there is clarity of title. The right solution of a quick movement to the "Torrens System" of title records and with the use of modern GPS technology (very cheap) to have absolute maps of properties is being missed. Indeed such exercises to clean up the title records could have been an important source of revenue for local bodies.

\section{URBAN NON-GOVERNANCE}

Urban infrastructure started getting attention after years of neglect, in the nineties. After the Constitutional Amendments $-73^{\text {rd }}$ and $74^{\text {th }}$ which created the third level of governance at the habit level (Village and City Levels), with elections being conducted for constitution of the governments at the local level. The demand for local government at the village level, had always had the support of the "Gandhians" and others -who believed that village level governance would take India to the modern world on the idiom and re-construction of its hypothesised "historical" past of village communities. Support for the same also came from the failure of the government to deliver in an effective manner its vast programmes all of them attempting to address "rural development". The few successes could actually be attributed to the pressures exerted by civil society organizations (MP in the area operated by the SPS) and /or the idiosyncratic pursuit by particular civil servants beyond the normal call of duty. Interestingly, there has been little success in terms of infrastructure creation around habits and their proper functioning, the debate continues among social scientists on the reasons for failure, unless of course the very fact of there being elected governments at the local level is taken as an indicator of success. However, the reasons for failure when one approaches the problem with the perspective of public organizations and incentive compatibility in organizations are not far to seek.

In the first instance the law ( $74^{\text {th }}$ Amendment) to cover the urban local bodies itself was an afterthought. Literally the same was crafted overnight and the rules governing the law were still pending and were hurriedly put in place. There was no political demand for local self government at the urban level. 
When the rules emerged they did not grant power over the organization to the elected. Indeed no mayor could determine policy or priorities, and most importantly the staff was not accountable to the mayor but to the state bureaucracy, forget about the elected being able to choose their staff as in common is serious democracies. Neither are the officials empowered since they cannot go ahead without the consent of the elected and the tokenism of approval by the mayor takes its toll in the bureaucracy being unable to function. Not surprising therefore that people have over a period learnt that no-body can be held accountable and any good that can happen is only due to the luck factor of a particularly able knight who when he leaves would take the situation back to the mess it was.

As a result the issues even in ward elections are split on national political priorities and swings. In short the mismatch between authority and accountability is the root cause of the nonperformance of ULBs. The literature on the other hand has talked about the lack of capacity and skills as if these can be created in an organizations with perverse design and processes. Similarly, the earlier hope that if only finance were made available the ULBs would deliver - the plea in the immediate aftermath of the $74^{\text {th }}$ Amendment, when finally addressed through the setting up of the SFCs - did not result in change as we had then anticipated. Indeed, the first round of people who got elected as mayors were locally committed - not the typical politician. But that changed soon enough.

\section{Making the "political class"}

The lack of any opportunity to make "political capital" - the raison d etre of the politician - when denied completely (since there is no way he can promise good works or services and actually deliver them), would in the subsequent rounds of elections keep worthy individuals away and attract those willing to be make "money capital" on indulge in demagoguery, identity issues etc, the road to politics in India, given the all but negation of local representation through the "AntiDefection Law" as well. In this context there is no meaning in talking about training of mayors or elected nor even of the engineers or civil servants. The seniors who have some power to change the organization are all -typically IAS officers - who as soon as they are appointed to a municipal roles are looking for their next post in the centre or the state government, where for them career wise the real action is. IAS officers who could be as junior as 30-35 years old with only 
"collectors" experience are often placed above public health and road and PWD engineers of 50, creating virtually a caste system. These officers are harldy answerable to the elected either.

\section{Knights - but in shining armour}

Sometimes an exceptional civil servant when holding the position of commissioner, by rough riding the exant process, could by continuous exercise of personal leadership bring about change in performance, which is like a gift from heaven for the citizens, but this change being based not on change in the rules, the organization or its design has no institutional basis. So it gives way almost as soon as the officer is promoted and has to leave, to the municipality back to square one of being an organization without any coherence. The "success" of such officers then becomes legends and which are forceful for arguing why everything is an implementation issue and issue of not having good people or an issue of corruption further thereby postponing any systemic change.

So the real question is why at all does construction take place as when municipalities have funds under the JNNURM /UIDSSMTfor instance. All municipalities have large and small contractors for road works and civil construction. Typically the localization of the contractors in EPC is high with various kinds of local preferences but especially with barriers to entry and pressure of the businesses on each other. These organizations being keen to have construction and service contracts. And there are few controls, quality checks other than the minimal. In any case the EPC being usually piecemeal and not turnkey or even in logical packages, even when the best of processes are followed and there is genuine intent to get the best of the contractors, would result in high risks - emanating from the integration of the various pieces that constitute the infrastructure or service in question. Contractors would always have a wide variety of reasons typically delays on account of other contractors to justify their delays, besides people's resistance, land acquisition problems, and delayed payment itself. The resulting vicious circle of delays is legendary, and large public value losses are the order of the day resulting not only from these delays and cost overruns but also from the pain and nuisance to citizens and residents in the protracted construction and in complete absence of any kind of management or injunction to reduce this nuisance, forget about such clauses being part of the works order the contract. It is

only in the case of construction of metros by the DMRC and that too in a few cities that one can see some restraint on the contractors to avoid nuisance during the construction. In short, urban 
governance is in a mess where in reality nobody can be held accountable in a meaningful sort of way.

The result is that all efforts of feedback, documentation and highlighting of local level problems, while they have increased much and in ways that are interesting and provide significant inputs and ideas to improve the state of affairs, the system being without an incentive compatible organization (performing organization) can hardly use these reports. That they continue despite the obvious frustration speaks volumes of the hope that is there among Indian citizens - or at least among a few public spirited individuals, the media and NGOs.

\section{THE REAL ISSUES NOT IN THE DEBATE}

Standard prescriptions of governance reform such as transparency, accountability, and consultation and involvement of the people remain ineffective. Without the appropriate organizational structure including the autonomy for embedding responsibility, and with perverse processes and practices being actually in place by design, these prescriptions then lead to ritualized adherence at best with little or no impact on performance leaving only a confused set of civil society organizations and citizenry who then rant ad-nauseum the problem as one of individuals being corrupt. The occasional fact of a rough riding commissioner to show some performance temporarily further adds to the urban-legend of corruption as the problem.

\section{But change is possible}

The new government with a massive mandate has come to power in the centre with some experience of having made a change in the urban setting in Gujarat. It is true that whole of Gujarat thanks to the JGY programme of feeder separation and organizational reform of the successor companies of the GSEB was able to deliver $24 * 7$ power over all of Gujarat except for the IP sets used in agriculture where the committed 8 hours of supply is being made. As a result today none of the cities have regular power cuts. Besides the strategy of feeder separation, an essential component of the reform has been the grant of true autonomy to the electricity companies allowing them to bring professionals on the board and in key managerial positions, and in allowing them to manage their own affairs without the usual dysfunctional interference from the state bureaucracy or the politician. This kind of change was ignored by other states like 
Rajasthan which nevertheless pursued feeder separation, resulting in little or no gain unlike the case of Gujarat. The fact of $24 * 7$ power in Gujarat and especially in all its towns has been a major selling point in the political campaign of Mr. Modi. The issue of power sector reforms is important in itself. While there are interesting strategies to overcome the power problems they continue to remain in a quagmire of piecemeal and perhaps inappropriate approaches and even errors of reform, at least as yet. Essentially, direct subsidies to agriculturists and ushering in of full blown markets in power (for which the Indian system is more than ready) - day ahead and balancing markets for energy and capacity separately - with current contracts being cast as financial contracts, have the potential to liberate the sector very quickly. But it is doubtful whether this right approach is being considered by the government.

Similarly the fact of wide streets and much road construction, besides the release of ample land for urban activities in the cities of Gujarat, which have in their visibility to the middle classes of cities in other states created enormous acceptance of the agenda of development. But their success lie in the use of "TP schemes" - a process of land aggregation, Government instead of buying land from farmers and others in the periphery of the city, shrinks the plots of all by a standard fraction, uses TDRs and differential FSIs as further offsets, to protect the original relative value of every plot holder. The shrinkage allows government to get the land for infrastructure including roads which can then be laid out pretty well and quickly. Once $70 \%$ or so accept the conversion of their lands to new plots well market with road head etc the same becomes the map defining ownership and activity potential as well. Acceptance is very good since when correctly done the entire problem of acquisition can be avoided. Strangely this hugely successful approach is carried out under the Bombay Town Planning Act (now the Gujarat Town Planning Scheme) is not known to urban managers across the country!

Thus the root of problems of the current urban mess-up have deeper reasons:

(1) Inappropriate design of the organization of ULBs.

(2) Dysfunctional interfaces with state government bodies

(3) A whole host of inappropriate principles and approaches being used by planners

(4) Lack of even the most modicum of integration across urban functions

(5) Lack of a wholistic approach in the master plan to the layouts and transport infrastructure. 
(6) Neglect of widely available approaches such as use of TDRs, and auctions of FSI

(7) And above all the consensus on very low FSIs as being world class planning

All of these above are capable of being corrected through change in the law, grant of organizational autonomy, and re-working the planning staff to become true planners. Since the process of change can unlock humongous value both public and private overcoming the urban problems is actually fiscally rewarding as well. Comprehensiveness of approach, and the need for leadership with the ability to translate the demand for urban renewal and livable habits into "public value creation" is the only way forward. 